\title{
Environmental Epidemiology of Intestinal Schistosomiasis in Uganda: Population Dynamics of Biomphalaria (Gastropoda: Planorbidae) in Lake Albert and Lake Victoria with Observations on Natural Infections with Digenetic Trematodes
}

\author{
Candia Rowel, ${ }^{1}$ Besigye Fred, ${ }^{1}$ Martha Betson, ${ }^{2}$ Jose C. Sousa-Figueiredo, ${ }^{3,4}$ \\ Narcis B. Kabatereine, ${ }^{1}$ and J. Russell Stothard ${ }^{5}$ \\ ${ }^{1}$ Vector Control Division, Ministry of Health, 15 Bombo Road, P.O. Box 1661, Kampala, Uganda \\ ${ }^{2}$ Royal Veterinary College, Hawkshead Lane, North Mymms, Hatfield, Hertfordshire AL9 7TA, UK \\ ${ }^{3}$ Centro de Investigação em Saúde de Angola, Hospital Provincial, Rua Direita do Caxito, Bengo, Angola \\ ${ }^{4}$ Department of Life Sciences, Natural History Museum, Wolfson Wellcome Biomedical Laboratories, \\ Cromwell Road, London SW7 5BD, UK \\ ${ }^{5}$ Department of Parasitology, Liverpool School of Tropical Medicine, Pembroke Place, Liverpool L3 5QA, UK
}

Correspondence should be addressed to J. Russell Stothard; russell.stothardelstmed.ac.uk

Received 27 February 2014; Revised 16 June 2014; Accepted 30 September 2014

Academic Editor: Jacques Cabaret

Copyright (c) 2015 Candia Rowel et al. This is an open access article distributed under the Creative Commons Attribution License, which permits unrestricted use, distribution, and reproduction in any medium, provided the original work is properly cited.

\begin{abstract}
This study documented the population dynamics of Biomphalaria and associated natural infections with digenetic trematodes, along the shores of Lake Albert and Lake Victoria, recording local physicochemical factors. Over a two-and-a-half-year study period with monthly sampling, physicochemical factors were measured at 12 survey sites and all freshwater snails were collected. Retained Biomphalaria were subsequently monitored in laboratory aquaria for shedding trematode cercariae, which were classified as either human infective (Schistosoma mansoni) or nonhuman infective. The population dynamics of Biomphalaria differed by location and by lake and had positive relationship with $\mathrm{pH}(P<0.001)$ in both lakes and negative relationship with conductivity $(P=0.04)$ in Lake Albert. Of the Biomphalaria collected in Lake Albert $(N=6,183), 8.9 \%$ were infected with digenetic trematodes of which $15.8 \%$ were shedding S. mansoni cercariae and $84.2 \%$ with nonhuman infective cercariae. In Lake Victoria, $2.1 \%$ of collected Biomphalaria $(N=13,172)$ were infected with digenetic trematodes with $13.9 \%$ shedding $S$. mansoni cercariae, $85.7 \%$ shedding nonhuman infective cercariae, and $0.4 \%$ of infected snails shedding both types of cercariae. Upon morphological identification, species of Biomphalaria infected included B. sudanica, B. pfeifferi, and B. stanleyi in Lake Albert and B. sudanica, B. pfeifferi, and $B$. choanomphala in Lake Victoria. The study found the physicochemical factors that influenced Biomphalaria population and infections. The number and extent of snails shedding S. mansoni cercariae illustrate the high risk of transmission within these lake settings. For better control of this disease, greater effort should be placed on reducing environmental contamination by improvement of local water sanitation and hygiene.
\end{abstract}

\section{Introduction}

Digenetic trematodes of the genus Schistosoma are the causative agents of schistosomiasis in man and have an indirect life cycle with free swimming larval stages: miracidia that infect freshwater gastropod snail hosts and cercariae, shed from infected snails, that enter mammalian hosts by direct penetration across intact skin. Infection with S. mansoni gives rise to intestinal schistosomiasis and is transmitted by several species within the genus Biomphalaria [1]. In Uganda, the distribution of Biomphalaria is countrywide although certain species may be restricted; for example, in the basin of Lake Victoria, B. sudanica, B. choanomphala, and B. pfeifferi are found, whereas in Lake Albert B. sudanica, B. stanleyi, and 
B. pfeifferi are the predominate species [1]. This interpretation was revised upon molecular characterization of sampled snails by detection of $B$. choanomphala, as largely indistinguishable upon shell morphology with local B. stanleyi [2]. Typically, Biomphalaria generally prefers stagnant or slow moving water with low wave action and shows a high degree of tolerance to variation in the temperature of its habitat [3]. Such conditions, though not always, may also prove favorable for hatched miracidia to find and locate snails and in so doing establish patent infections that subsequently produce cercariae thereby fulfilling an essential epidemiological requirement [4].

Owing to an intricate host-parasite evolutionary interplay, trematodes are highly specific for their mollusc host and miracidia of $S$. mansoni only develop successfully within Biomphalaria [5]. Schistosome miracidia remain infective for about 8-12 hours after hatching and, even if in nonflowing water, can disperse over distances of at least $5 \mathrm{~m}$ from the source of origin [6]. After the miracidium penetrates the epithelium of the snail, successful establishment depends on mitigating molluscan immunity which is both cellular and humoral $[5,7,8]$. The miracidium develops into primary sporocysts and secondary sporocysts that thence liberate cercariae, being shed from the snail typically bursting host tissues. Under favourable conditions, this prepatent period or cercarial incubation period lasts for a minimum of approximately three weeks and varies widely according to the host/parasite combination and environmental factors, especially temperature (reviewed by [9-14]). Once patent, an individual snail may shed cercariae for several months, more or less continuously [15]. As these larval stages often have unique morphological features and characteristics, identification of cercariae can be accomplished by visual examination under the dissecting microscope, timing of cercarial emergence, and their swimming characteristics $[16,17]$. Owing to this incubation period, if a field caught snail is not presently shedding cercariae, it may be incubating an infection which becomes later patent some 3-4 weeks later.

Biomphalaria are generally tolerant over wide ranges of the commonly measured chemical and physical variables in fresh waters; however, increased saline concentration is an important factor in preventing schistosomiasis transmission [1]. Although the snail hosts of schistosomes tolerate a wide range of environmental conditions, their local distribution may be patchy, often showing marked aggregations along short distances of the margin of a lake or stream. Patchiness in snail distribution reflects factors such as protection from water flow, wave action, and desiccation, availability of food, presence of vegetation, and suitable surfaces for attachment $[1,14]$. Spatial variation in the prevalence of patent snail infection is related, essentially, to the force of infection; that is, supply of miracidia derived from human excreta (for S. mansoni) which can also induce local snail mortality if infected by multiple miracidia. The chances that infection will develop to patency within an individual snail depend on genetic constitution, age, and length of prepatent period compared with snail life expectancy. This is equally true for infections in snails caused zoonotic schistosome species or by other trematodes that infect vertebrates other than man [18-20]. Many studies, however, have observed surprisingly low prevalences of patent snail infections in known schistosomiasis transmission sites $[1,13,21]$, whilst increased abundance of Biomphalaria and transmission of S. mansoni in other sites are perhaps consequences of the construction of antisalinity barrage, engineering works which impede tidal flow [22-25] and environmental and climatic factors such as local geography, temperature, and rainfall [10-12, 26]. Some of these factors have been investigated at a local level in Lake Albert [27] and Lake Victoria [28], but as yet a detailed assessment through a longer monitoring period is lacking.

To shed light on the longer term patterns in the environmental epidemiology of intestinal schistosomiasis in Lake Victoria and Lake Albert in Uganda and compare and contrast settings, this study investigated the population dynamics of Biomphalaria and natural infections with trematodes, over a two-year study period and by assessing for relationships with local physicochemical factors.

\section{Materials and Methods}

2.1. Study Design and Area. An observational and analytic study was conducted along the Ugandan shores of Lake Albert and Lake Victoria at six locations: Bugoigo $\left(\mathrm{N} 01.90849^{\circ} \quad\right.$ E031.40963 ${ }^{\circ} \quad$ Elev.: $\left.615 \mathrm{~m}\right)$, Walukuba (N01.84235 ${ }^{\circ}$ E031.37823 Elev.: $617 \mathrm{~m}$ ), and Piida (N01.81950 E031.32818 Elev.: 618) in Buliisa District (Lake Albert) and Bugoto (N00.30900 E033.62154 Elev.: $1153 \mathrm{~m}$ ), Lwanika $\left(\mathrm{N} 00.35109^{\circ}\right.$ E033.446019 ${ }^{\circ}$ Elev.: $1128 \mathrm{~m}$ ), and Bukoba (N00.31265 ${ }^{\circ}$ E033.49294 Elev.: $1133 \mathrm{~m}$ ) in Mayuge District (Lake Victoria) (see Figure 1). At each site, snail collections were performed at the lake edge, which was often marshy, designated site $A$, and at depth $(\sim 1 \mathrm{~m})$ in the lake as designated site B. The study was conducted from January 2009 to May 2011 and typically involved coordinated sampling at each site in a monthly timetable.

2.2. Study Site Selection and Sampling Protocol. The study was carried out as part of the Schistosomiasis in Mothers and Infants (SIMI) project, to sample snails at putative water contact sites where human activities like fetching, washing, and swimming took place (Figure 1). The aim was to later relate snail infection pattern to human infection with schistosomiasis. The sampled snails were sorted according to genera and the physicochemical factors were measured and observed.

2.3. Study Population. A total of 6,183 Biomphalaria snails were collected along the shores of Lake Albert and 13,172 Biomphalaria snails were collected along the shores of Lake Victoria in a period of 2 years and 5 months, with sampling done each month.

\subsection{Data Collection Methods}

2.4.1. Scooping Method. The snail scoop net was used for scooping for 40 minutes in each location with 20 minutes in site $\mathrm{A}$ and 20 minutes in site $\mathrm{B}$. The snails were put in a tray, 

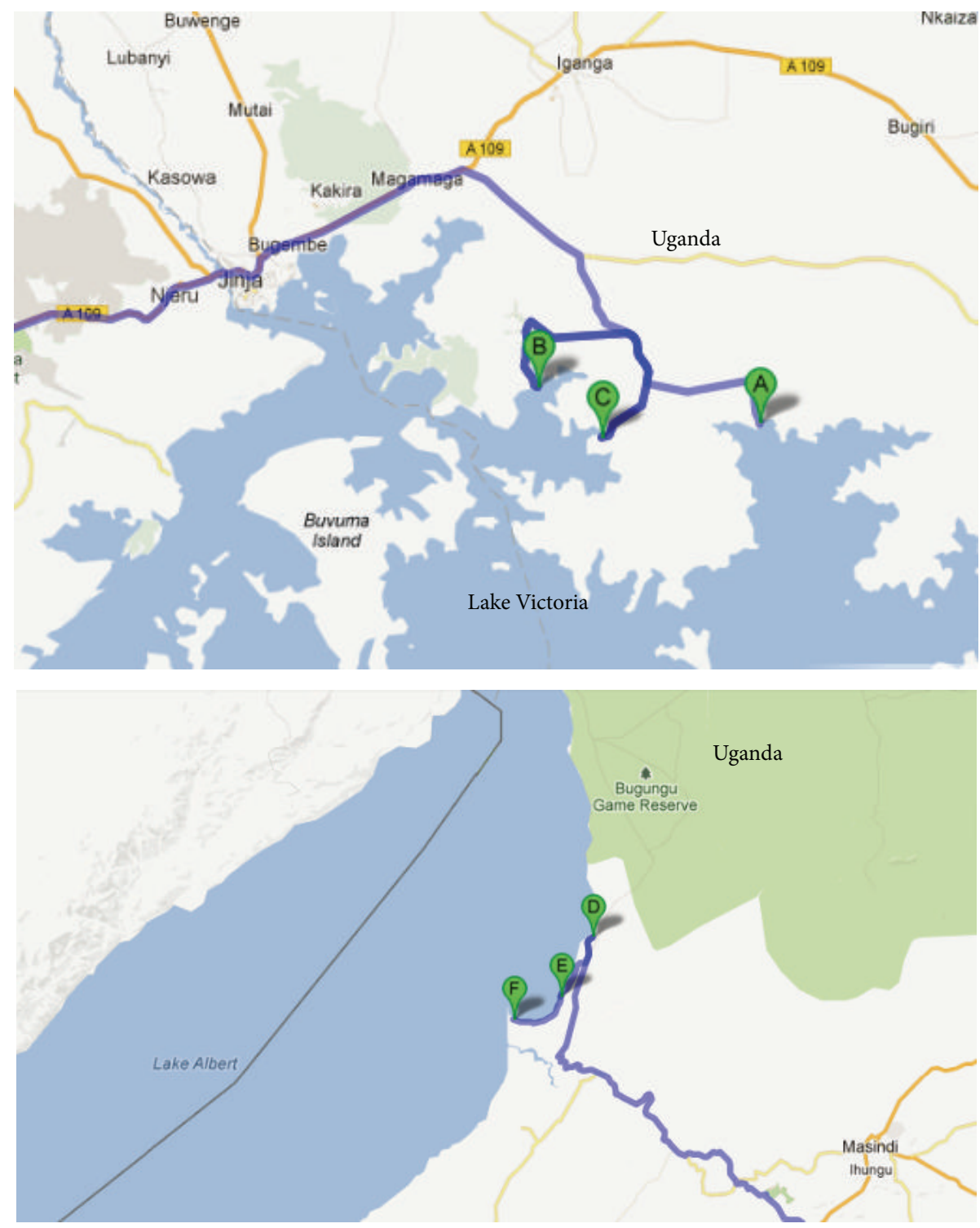
A: Bugoto
D: Bugoigo
B: Lwanika
E: Walukuba
C: Bukoba
F: Piida

FIGURE 1: Map showing the locations of Biomphalaria snail collection along Lake Victoria and Lake Albert.

sorted according to genus, thoroughly counted, and recorded on malacological form/proforma data sheets.

2.4.2. Physicochemical Factors Measurement. A water meter (430 Enterprise; Jenway Ltd, Stone, UK) was used to measure water chemistry and physical parameter including conductivity, total dissolved solute, $\mathrm{pH}$, and temperature. Water depth was measured using a calibrated water pole, Tinytag data loggers (Gemini Data Loggers, Chichester, UK) were also used to monitor the water temperature every 15 minutes, and observations on local wave actions, as made by eye, were used to assess wave exposure at the time of snail collection.

2.4.3. Laboratory Investigations. After collection from the sampling sites, the Biomphalaria snails were kept alive in aquaria for four weeks. Each week the snails are checked for cercarial shedding: snails were individually put in shedding trays with mineral water, exposed to natural light for 23 hours, and examined under a dissecting microscope for presence or absence of cercariae. The cercariae were identified by the general anatomical appearance [29]. The shedding Biomphalaria snails were identified to species level using shell morphology [1]. All the information was recorded on proforma data sheets.

2.5. Quality Control. Prior to the commencement of the study, the equipment and materials were tested for accuracy and reliability by carrying out a pilot study. To prevent personnel bias, two technicians carried out the surveys, working interchangeably between Lake Albert and Lake Victoria in 


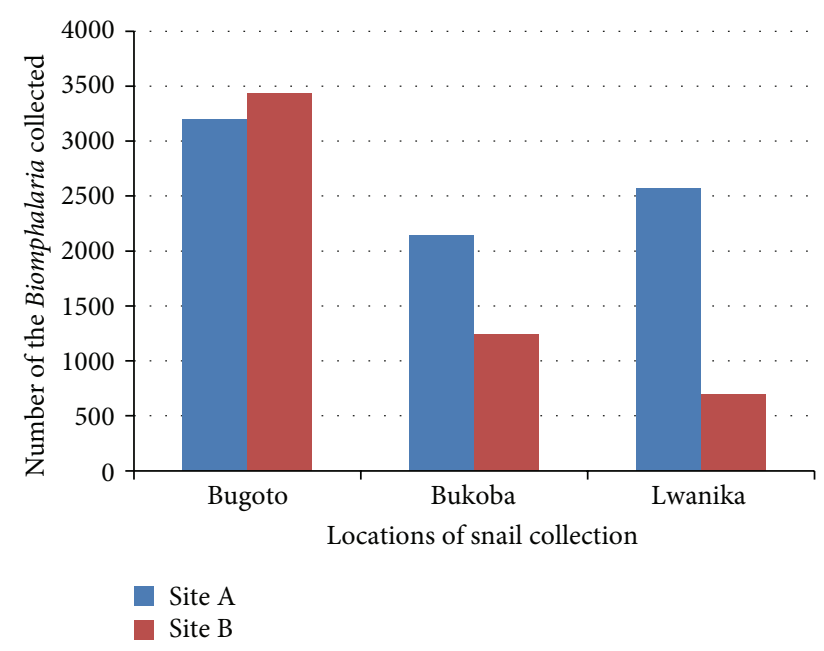

FIGURE 2: Biomphalaria population dynamics along Lake Victoria.

subsequent months. This was controlled for in the analyses and no significant effect of technician was observed (test statistic).

2.6. Data Handling and Statistical Analysis. Data on proforma data sheets were then transferred into electronic format using Microsoft Excel. The data collected were analyzed using STATA version 10.0. Biomphalaria infection prevalences were estimated and presented using tables and graphs. In order to determine physicochemical factors associated with abundance and infections of Biomphalaria snail at each Lake, a generalized linear model of Gaussian log function was applied. In this model, abundance and infections of snails were used as outcomes while independent variables included continuous variables, temperature, $\mathrm{pH}$, conductivity, and total dissolved solute, and categorical variables, wave action and weather. Coefficient, $P$ values, and $95 \%$ confidence interval $\left(\mathrm{CI}_{95}\right)$ were estimated for physicochemical factors. $P$ value $\leq 0.05$ was a measure of significance level. The arithmetic mean was chosen as the measure of central tendency.

2.7. Ethical Consideration. The study protocol was reviewed and approved by the Ethical Review Committee of the Uganda National Council for Science \& Technology (UNCST) and conducted within the framework of the ongoing Schistosomiasis Control Programme under the Vector Control Division (VCD), Ministry of Health.

\section{Results}

3.1. Biomphalaria Population Dynamics. There was variation in the number of Biomphalaria snails collected in different locations and sites despite the same period and duration of sampling used in all locations and sites. A total of 2,615 snails were sampled in Bugiogo, 2,081 in Walukuba, and 1,487 in Piida along the shores of Lake Albert (see Figure 3). In contrast, 6,530 Biomphalaria were collected in Bugoto, 3,260 in Lwanika, and 3,382 in Bukoba along the shores of Lake

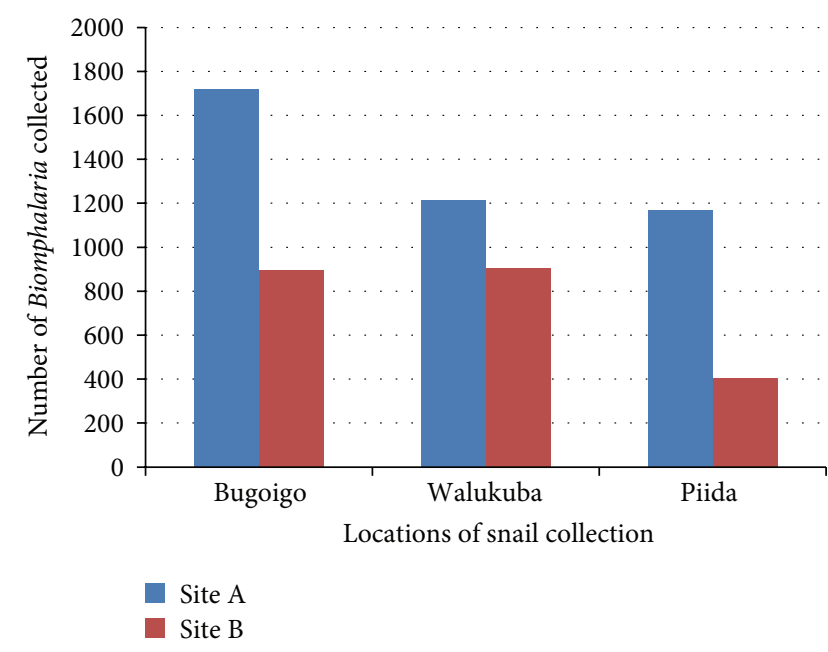

FIGURE 3: Biomphalaria population dynamics along Lake Albert.

Victoria (see Figure 2). This suggested that the Biomphalaria population was higher in Bugoigo and lower in Piida along Lake Albert and higher in Bugoto and lower in Lwanika along Lake Victoria. The Biomphalaria population also varied with site of snail collection in that the site A which was the shallow point had more Biomphalaria snails than site B which was a deeper point of snail collection along Lake Albert (see Figure 3). Along Lake Victoria, more Biomphalaria snails were found in site A than site B in Bukoba and Lwanika, whereas Bugoto had more Biomphalaria snails in site B than site A (see Figure 2).

3.2. The Physicochemical Factors. The physicochemical factors looked at included $\mathrm{pH}$, temperature, conductivity, and total dissolved solute (TDS). These parameters varied greatly between the locations, sites, and the water bodies (see Table 1). Among the physicochemical factors measured, conductivity and the total dissolved solute (TDS) were significantly higher along Lake Albert than Lake Victoria.

\subsection{Association of Biomphalaria Population Dynamics with} Physicochemical Factors. The Biomphalaria population showed positive relationship with the $\mathrm{pH}\left(P>0.001, \mathrm{CI}_{95}\right.$ 8.61-19.82) and negative relationship with the conductivity $\left(P=0.04, \mathrm{CI}_{95}-0.46\right.$ to -0.02$)$ along Lake Albert (see Table 2). However, along the shores of Lake Victoria, only $\mathrm{pH}$ showed a positive relationship with Biomphalaria population $\left(P>0.001, \mathrm{CI}_{95}\right.$ 15.60-27.68). Although TDS showed a positive relationship and conductivity showed a negative relationship along the shores of Lake Albert and Lake Victoria, respectively, they were not statistically significant ( $P=0.10$ and $P=0.37$, resp.). The temperature did not show any relationship with the Biomphalaria population dynamics along the two water bodies.

3.4. Biomphalaria Infection Rate. In Lake Albert, $8.9 \%$ $(551 / 6,183)$ of Biomphalaria were infected with trematodes of which $15.8 \%$ (87/551) were S. mansoni and 84.2\% (464/551) 
TABLE 1: The arithmetic mean of the physicochemical factors of water along Lake Albert and Lake Victoria.

\begin{tabular}{|c|c|c|c|c|}
\hline \multirow{2}{*}{ Sites of sample collection } & \multicolumn{4}{|c|}{ Arithmetic mean } \\
\hline & $\mathrm{pH}$ & Conductivity $(\mu \mathrm{s})$ & Total dissolved solute (ppm) & Temperature $\left({ }^{\circ} \mathrm{C}\right)$ \\
\hline \multicolumn{5}{|l|}{ Bugoigo } \\
\hline Site A & 8.38 & 619 & 398 & 28.7 \\
\hline Site B & 8.07 & 740 & 347 & 28.5 \\
\hline \multicolumn{5}{|l|}{ Walukuba } \\
\hline Site A & 8.86 & 660 & 373 & 28.2 \\
\hline Site B & 8.60 & 704 & 348 & 28.0 \\
\hline \multicolumn{5}{|l|}{ Piida } \\
\hline Site A & 7.72 & 999 & 568 & 27.8 \\
\hline Site B & 7.68 & 1081 & 516 & 27 \\
\hline \multicolumn{5}{|l|}{ Bugoto } \\
\hline Site A & 7.69 & 270 & 148 & 27.3 \\
\hline Site B & 8.62 & 112 & 58 & 27.7 \\
\hline \multicolumn{5}{|l|}{ Bukoba } \\
\hline Site A & 7.48 & 130 & 148 & 30.4 \\
\hline Site B & 7.43 & 132 & 58 & 29.1 \\
\hline \multicolumn{5}{|l|}{ Lwanika } \\
\hline Site A & 9.22 & 161 & 89 & 29.0 \\
\hline Site B & 8.53 & 165 & 62 & 28.6 \\
\hline
\end{tabular}

TABLE 2: Generalized linear model (GLM) of Biomphalaria population density with physicochemical factors of water.

\begin{tabular}{lccc}
\hline & Coefficient & $P>t$ & $\begin{array}{c}{[95 \% \text { confidence }} \\
\left.\text { interval, } \mathrm{CI}_{95}\right]\end{array}$ \\
\hline Lake Albert & & & \\
$\mathrm{pH}$ & 14.22 & $<\mathbf{0 . 0 0 1}$ & $8.61,19.82$ \\
$\quad$ Conductivity & -0.24 & $\mathbf{0 . 0 4}$ & $-0.46,-0.02$ \\
Lake Victoria & & & \\
$\mathrm{pH}$ & 21.64 & $<\mathbf{0 . 0 0 1}$ & $15.60,27.68$ \\
\hline
\end{tabular}

were nonhuman infective species (see Table 3). Along the shores of Lake Victoria, $2.1 \%(280 / 13,172)$ of snails were infected, with $13.9 \%(39 / 280)$ shedding S. mansoni cercariae, $85.7 \%(240 / 280)$ shedding nonhuman infective cercariae, and $0.4 \%(1 / 280)$ shedding multiple infections (both human infective and nonhuman infective cercariae) (see Table 4). The multiple infections were found in Bukoba and in the $B$. pfeifferi species.

The Biomphalaria infections were found in species $B$. sudanica, B. stanleyi, B. pfeifferi, and B. choanomphala, where $B$. sudanica, B. stanleyi, and B. pfeifferi were found along Lake Albert, and B. choanomphala, B. sudanica, and B. pfeifferi were found along Lake Victoria. The species most affected by both types of cercariae (human infective and nonhuman infective cercariae) were B. stanleyi along Lake Albert and $B$. pfeifferi along Lake Victoria. The most affected species with $S$. mansoni cercariae were B. stanleyi along Lake Albert and B. choanomphala along Lake Victoria. Walukuba and Bugoto, along Lake Albert and Lake Victoria, respectively, were the locations in which most of Biomphalaria infected with human infective cercariae were found (see Tables 3 and 4).
3.5. Biomphalaria Infections over Time. The Biomphalaria shedding cercariae were found throughout the months of the year. Biomphalaria shedding S. mansoni cercariae (human infective cercariae) were found in 22 months out of 26 months of the survey along Lake Albert and 11 months out of 24 months of survey along Lake Victoria (see Figures 4 and 5). Biomphalaria shedding nonhuman infective cercariae were found in 24 months out of 26 months of the survey along Lake Albert and all 24 months of Lake Victoria survey.

The fact that Biomphalaria shedding S. mansoni cercariae were found in most months of the year indicates continuous transmission of S. mansoni.

3.6. Factors Influencing Biomphalaria Infections. The Biomphalaria shedding $S$. mansoni cercariae had a positive relationship with Biomphalaria populations $\left(P=0.01, \mathrm{CI}_{95}\right.$ $0.002-0.014)$, a negative relationship with conductivity $(P=$ $0.05, \mathrm{CI}_{95}-0.003$ to -0.001$)$, and a positive relationship with temperature $\left(P=0.02, \mathrm{CI}_{95}\right.$ 0.011-0.123) along Lake Albert (see Table 5). A negative relationship with $\mathrm{pH}(P=0.05$, $\mathrm{CI}_{95}-0.44$ to -0.003$)$, a positive relationship with temperature ( $\left.P=0.03, \mathrm{CI}_{95} 0.008-0.130\right)$, and a positive relationship with slight wave action $\left(P=0.03, \mathrm{CI}_{95} 0.076-1.278\right)$ along Lake Victoria.

The Biomphalaria shedding nonhuman infective cercariae showed a positive relationship with temperature along Lake Albert $\left(P=0.008, \mathrm{CI}_{95} 0.111-0.706\right)$ and Lake Victoria $\left(P=0.004, \mathrm{CI}_{95}\right.$ 0.037-0.182) (see Table 6). However, there was a negative relationship with conductivity which was not statistically significant $(P=0.059)$, while the rest of the factors did not show any relationship with the Biomphalaria shedding nonhuman infective cercariae.

The water depth in which the Biomphalaria was found seemed to influence its infection where, along Lake Victoria, 
TABle 3: Biomphalaria infections along Lake Albert.

\begin{tabular}{|c|c|c|c|c|c|c|c|}
\hline \multirow{2}{*}{ Type of cercariae } & \multirow{2}{*}{$\begin{array}{l}\text { Proportion of infected } \\
\text { Biomphalaria }\end{array}$} & \multicolumn{3}{|c|}{ Species infected } & \multicolumn{3}{|c|}{ Location affected } \\
\hline & & B. sudanica & B. pfeifferi & B. stanleyi & Bugoigo & Walukuba & Piida \\
\hline $\begin{array}{l}\text { Human infective } \\
\text { cercariae (S. mansoni } \\
\text { cercariae) }\end{array}$ & $\begin{array}{c}15.8 \% \\
(87 / 551)\end{array}$ & $\begin{array}{c}25.3 \% \\
(22 / 87)\end{array}$ & $\begin{array}{c}5.7 \% \\
(5 / 87)\end{array}$ & $\begin{array}{c}69 \% \\
(60 / 87)\end{array}$ & $\begin{array}{c}27.6 \% \\
(24 / 87)\end{array}$ & $\begin{array}{c}63.2 \% \\
(55 / 87)\end{array}$ & $\begin{array}{c}9.2 \% \\
(8 / 87)\end{array}$ \\
\hline $\begin{array}{l}\text { Nonhuman infective } \\
\text { cercariae }\end{array}$ & $\begin{array}{c}84.2 \% \\
(464 / 551)\end{array}$ & $\begin{array}{c}45.5 \% \\
(211 / 464)\end{array}$ & $\begin{array}{c}11.6 \% \\
(54 / 464)\end{array}$ & $\begin{array}{c}42.9 \% \\
(199 / 464)\end{array}$ & $\begin{array}{c}47.6 \% \\
(221 / 464)\end{array}$ & $\begin{array}{c}43.1 \% \\
(200 / 464)\end{array}$ & $\begin{array}{c}9.3 \% \\
(43 / 464)\end{array}$ \\
\hline
\end{tabular}

TABLE 4: Biomphalaria infections along Lake Victoria.

\begin{tabular}{|c|c|c|c|c|c|c|c|}
\hline \multirow[b]{2}{*}{ Type of cercaria } & \multirow{2}{*}{$\begin{array}{l}\text { Proportion of infected } \\
\text { Biomphalaria }\end{array}$} & \multicolumn{3}{|c|}{ Species infected } & \multicolumn{3}{|c|}{ Location affected } \\
\hline & & B. sudanica & B. pfeifferi & $\begin{array}{l}\text { B. choanom- } \\
\text { phala }\end{array}$ & Bugoto & Lwanika & Bukoba \\
\hline $\begin{array}{l}\text { Human infective } \\
\text { cercariae (S. mansoni } \\
\text { cercariae) }\end{array}$ & $\begin{array}{c}13.9 \% \\
(39 / 280)\end{array}$ & $\begin{array}{l}22.5 \% \\
(9 / 40)\end{array}$ & $\begin{array}{c}20 \% \\
(8 / 40)\end{array}$ & $\begin{array}{c}57.5 \% \\
(23 / 40)\end{array}$ & $\begin{array}{c}50 \% \\
(20 / 40)\end{array}$ & $\begin{array}{l}17.5 \% \\
(7 / 40)\end{array}$ & $\begin{array}{c}32.5 \% \\
(13 / 40)\end{array}$ \\
\hline $\begin{array}{l}\text { Nonhuman infective } \\
\text { cercariae }\end{array}$ & $\begin{array}{c}85.7 \% \\
(240 / 280) \\
\end{array}$ & $\begin{array}{c}41.3 \% \\
(99 / 240)\end{array}$ & $\begin{array}{c}41.7 \% \\
(100 / 240) \\
\end{array}$ & $\begin{array}{c}17.1 \% \\
(41 / 240)\end{array}$ & $\begin{array}{c}13.8 \% \\
(33 / 240)\end{array}$ & $\begin{array}{c}49.2 \% \\
(118 / 240)\end{array}$ & $\begin{array}{c}37.1 \% \\
(89 / 240)\end{array}$ \\
\hline $\begin{array}{l}\text { Human infective } \\
\text { cercariae and nonhuman } \\
\text { infective cercariae } \\
\text { coinfections }\end{array}$ & $\begin{array}{c}0.4 \% \\
(1 / 280)\end{array}$ & $0 \%$ & $\begin{array}{c}100 \% \\
(1 / 1)\end{array}$ & $0 \%$ & $0 \%$ & $0 \%$ & $\begin{array}{c}100 \% \\
(1 / 1)\end{array}$ \\
\hline
\end{tabular}

TABLE 5: Generalized linear model (GLM) of Biomphalaria shedding S. mansoni cercaria with physicochemical factors of water and Biomphalaria population density along Lake Albert and Lake Victoria.

\begin{tabular}{lccc}
\hline & Coefficient $P>t$ & $\begin{array}{c}{[95 \% \text { confidence }} \\
\left.\text { interval, } \mathrm{CI}_{95}\right]\end{array}$ \\
\hline $\begin{array}{l}\text { L. Albert } \\
\text { Biomphalaria population }\end{array}$ & 0.01 & $\mathbf{0 . 0 1}$ & $0.002,0.014$ \\
$\begin{array}{l}\text { Conductivity } \\
\text { Temperature }\end{array}$ & -0.002 & $\mathbf{0 . 0 5 0}$ & $-0.003,-0.001$ \\
$\begin{array}{l}\text { Lake Victoria } \\
\text { pH }\end{array}$ & 0.07 & $\mathbf{0 . 0 2}$ & $0.011,0.123$ \\
Temperature & -0.22 & $\mathbf{0 . 0 5}$ & $-0.440,-0.003$ \\
$\quad$ Wave action (ref. calm) & 0.07 & $\mathbf{0 . 0 3}$ & $0.008,0.130$ \\
$\quad$ & & & \\
Slight & 0.68 & $\mathbf{0 . 0 3}$ & $0.076,1.278$ \\
\hline
\end{tabular}

TABLE 6: Generalized linear model (GLM) of Biomphalaria shedding nonhuman infective cercariae with physicochemical factors of water and Biomphalaria population density along Lake Albert and Lake Victoria.

\begin{tabular}{lccc}
\hline & Coefficient & $P>t$ & $\begin{array}{c}{[95 \% \text { confidence }} \\
\left.\text { interval, } \mathrm{CI}_{95}\right]\end{array}$ \\
\hline $\begin{array}{l}\text { L. Albert } \\
\text { Temperature }\end{array}$ & 0.409 & $\mathbf{0 . 0 0 8}$ & $0.111,0.706$ \\
$\begin{array}{l}\text { L. Victoria } \\
\text { Temperature }\end{array}$ & 0.110 & $\mathbf{0 . 0 0 4}$ & $0.037,0.182$ \\
\hline
\end{tabular}

shallow site A had more Biomphalaria shedding cercariae types than the deeper site B (see Figure 6). Along Lake Albert, the same situation was observed with nonhuman

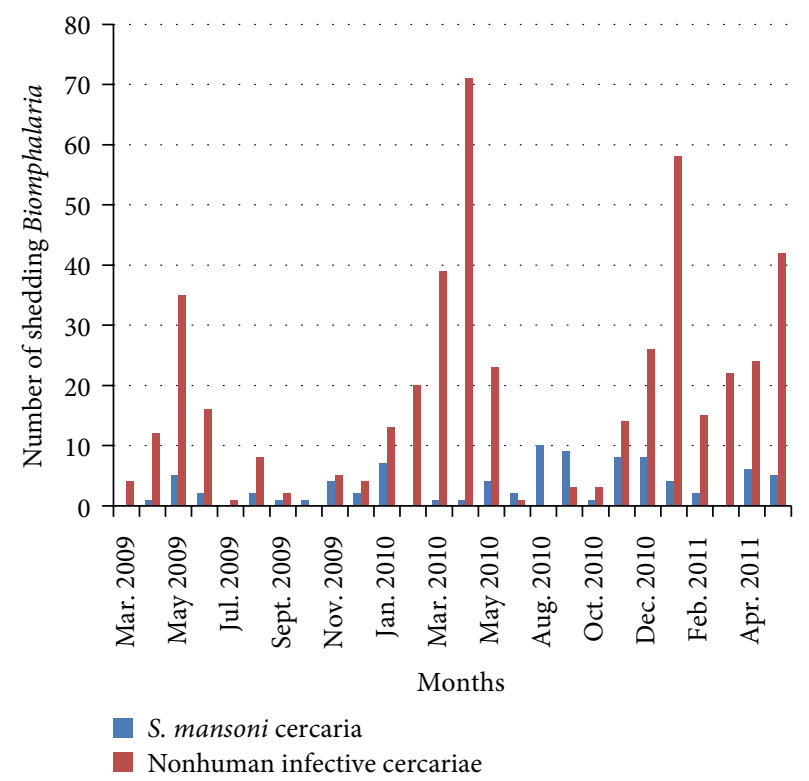

Figure 4: Temporal dynamics of Biomphalaria infections along Lake Albert.

infective cercariae with more Biomphalaria infection in site A than site B (see Figure 7), whereas it was not the case with Biomphalaria shedding human infective cercariae which had varied abundance in sites in different locations.

\section{Discussion}

This study evaluated the physicochemical factors, which affect the Biomphalaria population dynamics and infection 


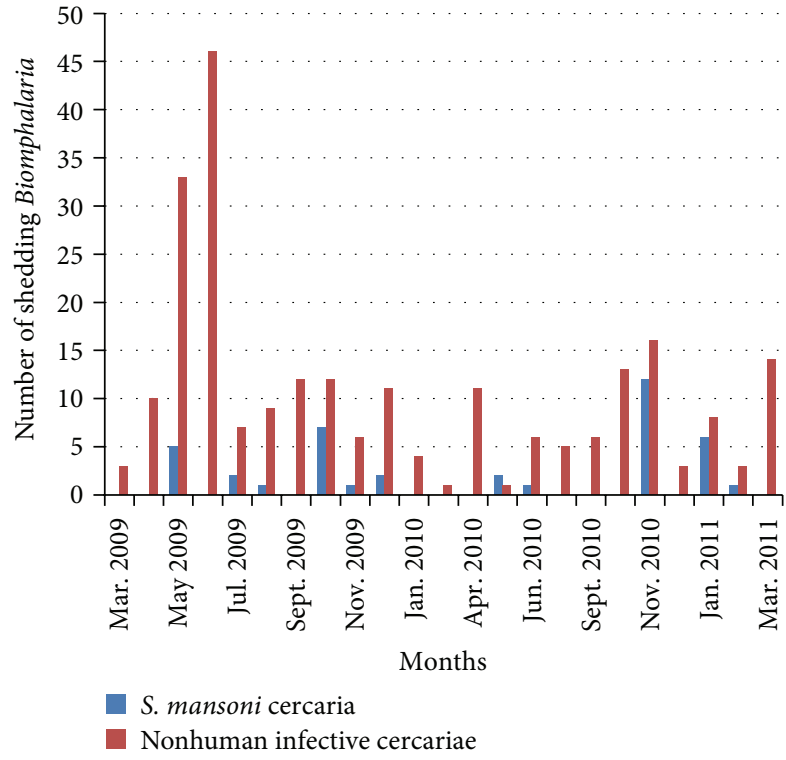

FIGURE 5: Temporal dynamics of Biomphalaria infections along Lake Victoria.

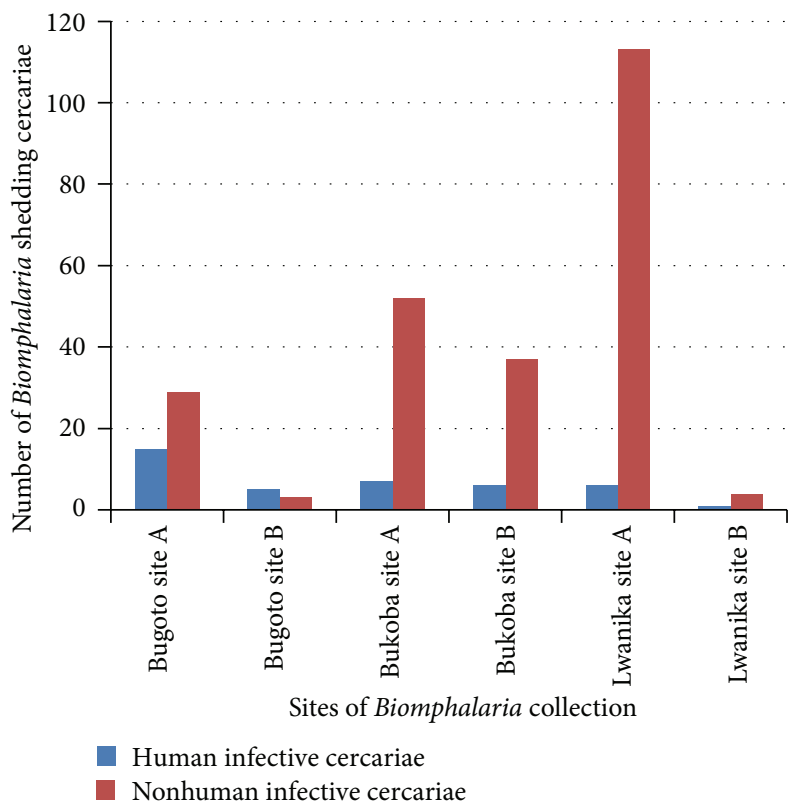

Figure 6: Biomphalaria shedding along Lake Victoria.

rates with trematode in its natural habitats along the Ugandan shores of Lake Albert and Lake Victoria. Like the associations presented by Standley et al. [28] and Levitz et al. [27], our results showed that some physicochemical factors had limited influence on Biomphalaria populations and associated trematode infections along the two water bodies. According to morphology, the most infected Biomphalaria species which shed S. mansoni cercariae were Biomphalaria stanleyi and Biomphalaria choanomphala; thus their control could significantly reduce $S$. mansoni transmission. Shedding was observed across most months of year, maintaining

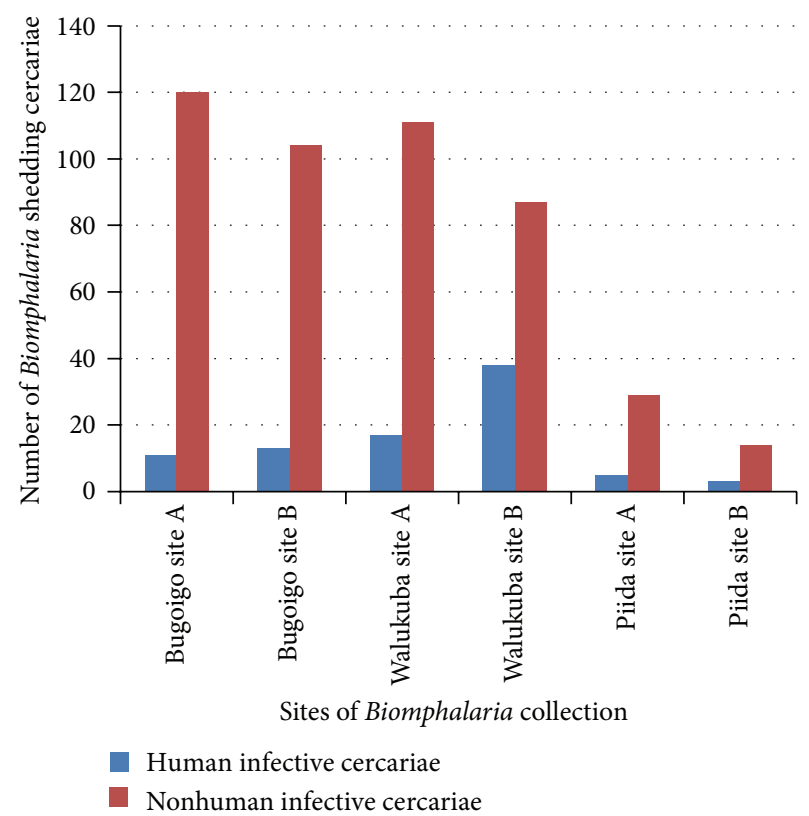

Figure 7: Biomphalaria shedding along Lake Albert.

transmission throughout; therefore, to achieve maximum control of schistosomiasis, we recommend that greater effort should be placed on reducing environmental contamination by improvement of local water sanitation and hygiene.

4.1. Biomphalaria Population Dynamics and Variation in Physicochemical Factors. The Biomphalaria snail collection was done in every location within the same period and duration. The total number of Biomphalaria snails collected in different locations and sites varied. This was found to be attributed to conductivity along Lake Albert, which varied between locations and sites. There was a negative relationship of conductivity with the Biomphalaria populations $(P=0.04)$ along the shores of Lake Albert which corresponds with other studies done along the same lake [30]. This was evident in Piida where conductivity values were the highest (Table 1), hence fewer Biomphalaria snails collected (Figure 3). $\mathrm{pH}$ was also shown to influence the Biomphalaria populations in the water bodies and showed a positive relationship with Biomphalaria populations $(P<0.001)$ (Table 2).

The differences in effect of some physicochemical factors on Biomphalaria populations in the two water bodies could be due to different locations in which the two water bodies are found [31-34], which allowed considerable difference in the values of the physicochemical factors of the water bodies. The site of the Biomphalaria collection seemed to determine its abundance, especially along Lake Albert and some locations along Lake Victoria, where the shallow site A had higher Biomphalaria population than deeper site B (Figures 2 and 3). This could be because of a greater availability of the food for the Biomphalaria in the shallow site A than in deeper site B [35].

4.2. Biomphalaria Infection Rate Status. Both the human infective cercariae (S. mansoni cercariae) and nonhuman 
infective cercariae were shed by the Biomphalaria in all locations and sites. The snails showed surprisingly low $S$. mansoni infection prevalences despite the fact that the locations of snail collection were hyperendemic for $S$. mansoni (Tables 3 and 4). The low prevalence of S. mansoni cercariae reported here was in line with other studies [13, 21]. It is likely that the use of molecular methods would lead to detection of a higher prevalence of snails infected with S. mansoni parasites [36].

The prevalence of coinfections of $S$. mansoni and nonhuman infective trematodes was low $(0.4 \%)$. This could be attributed to the physiological changes initiated by established trematodes in snails which can kill other invading trematodes or boost immune responses, a phenomenon termed behavioral fever [37-40]. This fact could be the explanation for the low Biomphalaria shedding human infective cercariae; for example, in the months in which more Biomphalaria were shedding nonhuman infective cercariae, there were fewer or no Biomphalaria shedding human infective cercariae (Figures 4 and 5). The Biomphalaria species involved in multiple infections was $B$. pfeifferi which corresponded with the species involved in Kenya [41] but contrasts with the species involved in multiple infections in Egypt, which was $B$. sudanica [41]. This could be because the surveys were carried along the same lake in the present study and in Kenya (Lake Victoria), which had similar environmental conditions which might have favoured coinfections in this particular species, whereas different water bodies were surveyed in Egypt.

The Biomphalaria species infected included B. sudanica, B. pfeifferi, and B. stanleyi along Lake Albert and B. sudanica, $B$. pfeifferi, and $B$. choanomphala along Lake Victoria. The presence of $B$. pfeifferi along Lake Albert has been doubtful, despite some studies reporting that snails closely resembling B. pfeifferi have been found in swamp areas of Lake Albert, Butiaba [42]. In additional studies to identify snails using molecular inferences and morphometry, of 18 specimens only a single specimen was identified as $B$. pfeifferi in Lake Albert [43]. These reports point to the potential presence of $B$. pfeifferi along Lake Albert; however, further confirmatory studies are required.

The S. mansoni cercariae prevalence was highest in Walukuba and Bugoto along Lake Albert and Lake Victoria, respectively, which hold $50 \%$ or more of the infected snails (Tables 3 and 4). However, previous studies done along Lake Albert in the same locations showed different results, where snails from Piida and Bugoigo had the highest schistosome infection rates [44]. This could mean that transmission rates at locations depend on human activities at each location which can change over time. The most commonly infected Biomphalaria species in this study were B. stanleyi and B. choanomphala along Lake Albert and Lake Victoria, respectively, where the finding along Lake Albert agreed with previous studies from Lake Albert which showed infection prevalence to be significantly higher in B. stanleyi $[44,45]$ and report along Lake Victoria indicated B. choanomphala a most efficient vector [46]. This information could be utilized to specifically target controlling these species in the water bodies to help in the control of schistosomiasis in these areas.
4.3. Biomphalaria Infection Patterns. The Biomphalaria snails shed nonhuman infective cercariae and S. mansoni cercariae. Both types of cercariae were shed in most months of the surveys in both lakes (Figures 4 and 5). This revelation casts doubt on the effectiveness of mass drug administration for schistosomiasis which is done once a year in these areas. As reinfection of people is inevitable, there is a need to rethink the strategy for schistosomiasis control in these areas which could prevent snail infection like sanitation improvement. The Biomphalaria shedding was found more in site A than site B along Lake Victoria and some location of Lake Albert (Figures 5 and 6). This fact could also be used in control strategy of schistosomiasis in that intensive snail control done in shallow margin of the lake, which would not have serious effect on ecosystem of the lakes but help in control of schistosomiasis.

4.4. Factors Influencing Biomphalaria Shedding. The Biomphalaria shedding $S$. mansoni cercariae showed a positive relationship with Biomphalaria population size $(P=0.01$, $\mathrm{CI}_{95}$ 0.002-0.014) along Lake Albert. This was probably due to the fact that a higher population density of snails could promote parasite transmission as the access distance for the miracidia is reduced; hence more snails get infected, which could be the reason as to why the location with the lowest Biomphalaria abundance had least Biomphalaria infections (Figure 3 and Table 3). There was a negative relationship with conductivity ( $P=0.05, \mathrm{CI}_{95}-0.003$ to -0.001$)$ along Lake Albert. This could explain the low Biomphalaria infection along Lake Albert in the location with the highest conductivity values (Piida) (Figure 7). Temperature showed a positive relationship with $S$. mansoni cercarial shedding $\left(P=0.02, \mathrm{CI}_{95}\right.$ 0.011-0.123) along Lake Albert. This could be attributed to the favourable temperature at this location (arithmetic mean $27^{\circ} \mathrm{C}-28.7^{\circ} \mathrm{C}$ ) which could have influenced the development and survival of the intramolluscan stages of schistosomes [10-12].

Along Lake Victoria there was negative relationship of the Biomphalaria snails shedding $S$. mansoni cercariae with $\mathrm{pH}$ $\left(P=0.05, \mathrm{CI}_{95}-0.440\right.$ to -0.003$)$, but, considering the $\mathrm{pH}$ values in the two water bodies, there was not much difference (Table 1) which could mean the effect was influenced by other factors along this water body [47]; for example, the $\mathrm{pH}$ and temperature could have effect on the physiology and maturation rates of the parasite in the vector [48]. Temperature had a positive relationship with shedding $(P=$ $0.03, \mathrm{CI}_{95}$ 0.008-0.130) which could be attributed to the temperature range (Table 1) that influenced the development and survival of the intramolluscan stages of the cercariae [10-12]. In addition, slight wave action showed a positive relationship ( $\left.P=0.03, \mathrm{CI}_{95} 0.076-1.278\right)$ (Table 5), which could be as a result of the increased contact between the snails and the miracidia that infect the snails more in a water body with slight wave action than in calm water. However, the difference in effect of some of the physicochemical factors along Lake Albert and Lake Victoria could be the fact that they are in different water bodies in which these factors exert varied effect [31-34]. 
Meanwhile, the Biomphalaria shedding nonhuman infective cercariae had positive relationship with temperature in both Lake Albert and Lake Victoria $\left(P=0.008, \mathrm{CI}_{95}\right.$ $0.111-0.706$ and $P=0.04, \mathrm{CI}_{95}$ 0.037-0.182). This could be because the temperature provided favourable condition which could have influenced the development and survival of the intramolluscan stages of the cercariae [10-12].

\section{Conclusion}

This study revealed that the physicochemical factors influencing the Biomphalaria population were conductivity, water depth, and $\mathrm{pH}$, whereas those that influenced Biomphalaria infections were temperature, $\mathrm{pH}$, slight wave action, water depth, conductivity, and Biomphalaria population density. Both human infective cercariae and nonhuman infective cercariae were shed by Biomphalaria. The shedding spread across most of the months of year, hence maintaining transmission throughout the year; therefore, in order to achieve maximum control of schistosomiasis, we recommend greater effort should be placed on reducing environmental contamination by improvement of local water sanitation and hygiene.

\section{Highlights}

(i) Investigation into the effect of physicochemical factors on Biomphalaria population dynamics.

(ii) Investigation into the effect of physicochemical factors on Biomphalaria infection in its natural habitat.

(iii) Differentiating the cercariae types into human infecting and nonhuman infecting types, based on pattern of emergence and morphological appearance.

(iv) Establishment of Biomphalaria species infected and locations in which they are found.

\section{Conflict of Interests}

The authors declare that there is no conflict of interests regarding the publication of this paper.

\section{Authors' Contribution}

Candia Rowel was involved in data collection, analysis, interpretation, and drafting of the paper. Besigye Fred was involved in data collection, analysis, and revising the paper. Martha Betson contributed to study design, sample analysis, and critical revising of the paper. Jose C. SousaFigueiredo participated in study design, data analysis, and critical revising of the paper. Narcis B. Kabatereine was involved in supervision and critical revising of the paper. J. Russell Stothard carried out study design, solicited funds, supervision, and critical revising of the paper.

\section{Acknowledgments}

The study was financially supported by Wellcome Trust Project Grant. The authors thank the administrations of the districts where the study was done and staff of Vector Control Division for their cooperation ensuring success of the study especially Benjamin Tinkitina for analyzing the data.

\section{References}

[1] D. S. Brown, "Distribution and abundance of snails, brackish water: prevalence of infected snails spatial variation," in Fresh Water Snails of Africa and Their Medical Importance, pp. 317318, Taylor \& Francis, 1994.

[2] M. Plam, A. Jørgensen, T. K. Kristensen, and H. Madsen, "Sympatric Biomphalaria species (Gastropoda: Planorbidae) in Lake Albert, Uganda, show homoplasies in shell morphology," African Zoology, vol. 43, no. 1, pp. 34-44, 2008.

[3] FAO, "Aquaculture and schistosomiasis," Corporate Document Repository, 2013, http://www.fao.org/documents/.

[4] P. C. Beaver, R. C. Jung, and E. W. Cupp, "Schistosomes or blood flukes," in Clinical Parasitology, chapter 27, pp. 415-448, Lea and Febiger, 1984.

[5] W. P. W. van der Knaap and E. S. Loker, "Immune mechanisms in trematode-snail interactions," Parasitology Today, vol. 6, no. 6, pp. 175-182, 1990.

[6] P. Jordan and G. Webbe, Schistosomiasis Epidemiology: Treatment and Control, William Heinemann Medical Books, London, UK, 1982.

[7] C. J. Bayne and E. S. Loker, "Survival within the snail host," in Biology of Schistosomes, D. Rollinson and A. J. G. Simpson, Eds., pp. 321-346, Academic Press, London, UK, 1987.

[8] T. M. Preston and V. R. Southgate, "The species specificity of Bulinus-Schistosoma interactions," Parasitology Today, vol. 10, no. 2, pp. 69-73, 1994.

[9] E. S. Loker, "A comparative study of the life-histories of mammalian schistosomes," Parasitology, vol. 87, no. 2, pp. 343369, 1983.

[10] R. J. Pitchford, "The use of behaviour patterns of larval schistosomes in assessing the bilharzia potential of non-endemic areas," South African Medical Journal, vol. 43, no. 32, pp. 983995, 1969.

[11] C. J. Shiff, A. Evans, C. Yiannakis, and M. Eardley, "Seasonal influence on the production of Schistosoma haematobium and S. mansoni cercariae in Rhodesia," International Journal for Parasitology, vol. 5, no. 1, pp. 119-123, 1975.

[12] R. J. Pitchford, "Temperature and schistosome distribution in South Africa," South African Journal of Science, vol. 77, no. 6, pp. 252-261, 1981.

[13] M. E. J. Woolhouse and S. K. Chandiwana, "Spatial and temporal heterogeneity in the population dynamics of Bulinus globosus and Biomphalaria pfeifferi and in the epidemiology of their infection with schistosomes," Parasitology, vol. 98, no. 1, pp. 21-34, 1989.

[14] M. E. J. Woolhouse and S. K. Chandiwana, "The epidemiology of schistosome infections of snails: taking the theory into the field," Parasitology Today, vol. 6, no. 3, pp. 65-70, 1990.

[15] S. E. Fryer and A. J. Probert, "The cercarial output from three Nigerian bulinids infected with two strains of Schistosoma haematobium," Journal of Helminthology, vol. 62, no. 2, pp. 133140, 1988. 
[16] F. Mouchet, A. Theron, P. Bremond, E. Sellin, and B. Sellin, "Pattern of cercarial emergence of Schistosoma curassoni from Niger and comparison with three sympatric species of schistosomes," Journal of Parasitology, vol. 78, no. 1, pp. 61-63, 1992.

[17] C. Vera, F. Mouchet, P. Bremond, A. Sidiki, E. Sellin, and B. Sellin, "Natural infection of Bulinus senegalensis by Schistosoma haematobium in a temporary pool focus in Niger: characterization by cercarial emergence patterns," Transactions of the Royal Society of Tropical Medicine and Hygiene, vol. 86, no. 1, p. 62, 1992.

[18] E. A. Malek, Snail-Transmitted Parasitic Diseases, vol. 1-2, CRC Press, Boca Raton, Fla, USA, 1980.

[19] F. M. A. Ukoli, Introduction of Parasitology in Tropical Africa, John Wiley \& Sons, New York, NY, USA, 1984.

[20] S. Geerts, V. Kamar, and J. Brandt, Eds., Helminth Zoonoses, Martinus Nijhoff, Dordrecht, The Netherlands, 1987.

[21] J. B. Tucker, "Schistosomiasis and water projects: breaking the link," Environment, vol. 25, no. 7, pp. 17-20, 1983.

[22] O. T. Diaw, G. Vassiliadès, and Y. Sarr, "Prolifération de molluusque après la consruction du Barrage de Diama au Sénégal," Bulletin de la Société Francaise de Parasitologie, vol. 8, supplement 2, p. 772, 1990.

[23] I. Talla, A. Kongs, P. Verlé, J. Belot, S. Sarr, and A. M. Coll, "Outbreak of intestinal schistosomiasis in the Senegal River Basin," Annales de la Société Belge de Médecine Tropicale, vol. 70, no. 3, pp. 173-180, 1990.

[24] J. P. Chippaux, A. Massougbodji, A. Zomadi, and B. M. Kindafodji, "Edute épidémiologiue dans un complexe lacustre cotier de formation récente," Bulletin de la Société de Pathologie Exotique, vol. 83, pp. 498-509, 1990.

[25] C. C. Appleton and M. N. Bruton, "The epidemiology of schistosomiasis in the vicinity of Lake Sibaya, with a note on other areas of Tongaland (Natal, South Africa)," Annals of Tropical Medicine and Parasitology, vol. 73, no. 6, pp. 547-561, 1979.

[26] P. Taylor and O. Makura, "Prevalence and distribution of schistosomiasis in Zimbabwe," Annals of Tropical Medicine and Parasitology, vol. 79, no. 3, pp. 287-299, 1985.

[27] S. Levitz, C. J. Standley, M. Adriko, N. B. Kabatereine, and J. R. Stothard, "Environmental epidemiology of intestinal schistosomiasis and genetic diversity of Schistosoma mansoni infections in snails at Bugoigo village, Lake Albert," Acta Tropica, vol. 128, no. 2, pp. 284-291, 2013.

[28] C. J. Standley, P. Vounatsou, L. Gosoniu et al., "Microscale investigation of intestinal schistosomiasis transmission on Ngamba and Kimi islands, Lake Victoria, Uganda," Acta Tropica, vol. 128, no. 2, pp. 353-364, 2013.

[29] F. Frandsen and N. O. Christensen, "An introductory guide to the identification of cercariae from African freshwater snails with special reference to cercariae of trematode species of medical and veterinary importance," Acta Tropica, vol. 41, no. 2, pp. 181-202, 1984.

[30] F. A. Donelly, C. C. Appleton, G. W. Begg, and C. H. J. Schutte, "Bilharzia transmission in Natal's estuaries and lagoons: fact or fiction?" South African Journal of Science, vol. 80, no. 10, pp. 455-460, 1984.

[31] B. C. Dazo, N. G. Hairston, and I. K. Dawood, "The ecology of Bulinus truncatus and Biomphalaria alexandrina and its implications for the control of bilharziasis in the Egypt-49 project area," Bulletin of the World Health Organization, vol. 35, no. 3, pp. 339-356, 1966.
[32] R. K. Klumpp and K. Y. Chu, "Ecological studies of Bulinus rohlfsi, the intermediate host of Schistosoma haematobium in the Volta Lake," Bulletin of the World Health Organization, vol. 55, no. 6, pp. 715-730, 1977.

[33] A. M. A. Imevbore, I. E. Ofoezie, and E. A. Obot, "Vector borne disease problems of small scale water recourses development project in Kano state, 1 . Snail vector of schistosomiasis," The Afrancet, vol. 1, pp. 17-23, 1988.

[34] I. E. Ofoezie, "Distribution of freshwater snails in the manmade Oyan Reservoir, Ogun State, Nigeria," Hydrobiologia, vol. 416, pp. 181-191, 1999.

[35] M. Loreau and B. Baluku, "Population dynamics of the freshwater snail Biomphalaria pfeifferi in Eastern Zaïre," Journal of Molluscan Studies, vol. 53, no. 3, pp. 249-265, 1987.

[36] A. Born-Torrijos, R. Poulin, J. A. Raga, and A. S. Holzer, "Estimating trematode prevalence in snail hosts using a single-step duplex PCR: how badly does cercarial shedding underestimate infection rates?" Parasites \& Vectors, vol. 7, article 243, 2014.

[37] A. E. Bates, F. Leiterer, M. L. Wiedeback, and R. Poulin, "Parasitized snails take the heat: a case of host manipulation?" Oecologia, vol. 167, no. 3, pp. 613-621, 2011.

[38] S. M. Bronstein and W. E. Conner, "Endotoxin-induced behavioural fever in the Madagascar cockroach, Gromphadorhina portentosa," Journal of Insect Physiology, vol. 30, no. 4, pp. 327-330, 1984.

[39] K. Myhre, M. Cabanac, and G. Myhre, "Fever and behavioural temperature regulation in the frog Rana esculenta," Acta Physiologica Scandinavica, vol. 101, no. 2, pp. 219-229, 1977.

[40] H. A. Bernheim and M. J. Kluger, "Fever and antipyresis in the lizard Dipsosaurus dorsalis," American Journal of Physiology, vol. 231, no. 1, pp. 198-203, 1976.

[41] W. M. Lotfy, B. Hanelt, G. M. Mkoji, and E. S. Loker, "Genotyping natural infections of Schistosoma mansoni in Biomphalaria alexandrina from Damietta, Egypt, with comparisons to natural snail infections from Kenya," Journal of Parasitology, vol. 97, no. 1, pp. 156-159, 2011.

[42] N. B. Kabatereine, Schistosoma mansoni in fishing community on the shores of Lake Albert at Butiaba, Uganda: Epidemiology, morbidity, re-infection patterns and impact of treatment with praziquantel [Ph.D. thesis], Vector Control Division, Ministry of Health, Uganda, and Faculty of Science, University of Copenhagen and DBL-Centre for Health Research and Development, 2000.

[43] P. Maria, A. Jørgensen, T. K. Kristensen et al., "Sympatric Biomphalaria species (Gastropoda: Planorbidae) in Lake Albert, Uganda, show homoplasies in shell morphology," African Zoology, vol. 43, no. 1, 2008, http://africanzoology.journals.ac.za.

[44] F. Kazibwe, B. Makanga, C. Rubaire-Akiiki et al., "Ecology of Biomphalaria (Gastropoda: Planorbidae) in Lake Albert, Western Uganda: snail distributions, infection with schistosomes and temporal associations with environmental dynamics," Hydrobiologia, vol. 568, no. 1, pp. 433-444, 2006.

[45] F. Kazibwe, B. Makanga, C. Rubaire-Akiiki et al., "Transmission studies of intestinal schistosomiasis in Lake Albert, Uganda and experimental compatibility of local Biomphalaria spp," Parasitology International, vol. 59, no. 1, pp. 49-53, 2010.

[46] M. Adriko, C. J. Standley, B. Tinkitina et al., "Compatibility of Ugandan Schistosoma mansoni isolates with Biomphalaria snail species from Lake Albert and Lake Victoria," Acta Tropica, vol. 128, no. 2, pp. 303-308, 2013. 
[47] T. T. Macan, Freshwater Ecology, Longman, London, UK, 2nd edition, 1974.

[48] N. Singh, K. Pradeep, and D. Kumar Singh, "Variant abiotic and the Faciola gigantic larval stages in vector Indoplanorbis exustus," Journal of Biology and Earth Sciences, vol. 2, no. 2, pp. B110-B117, 2012. 


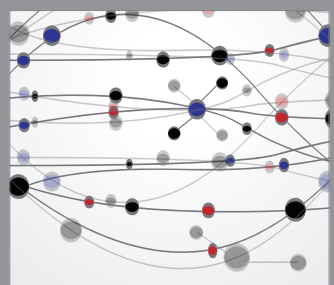

The Scientific World Journal
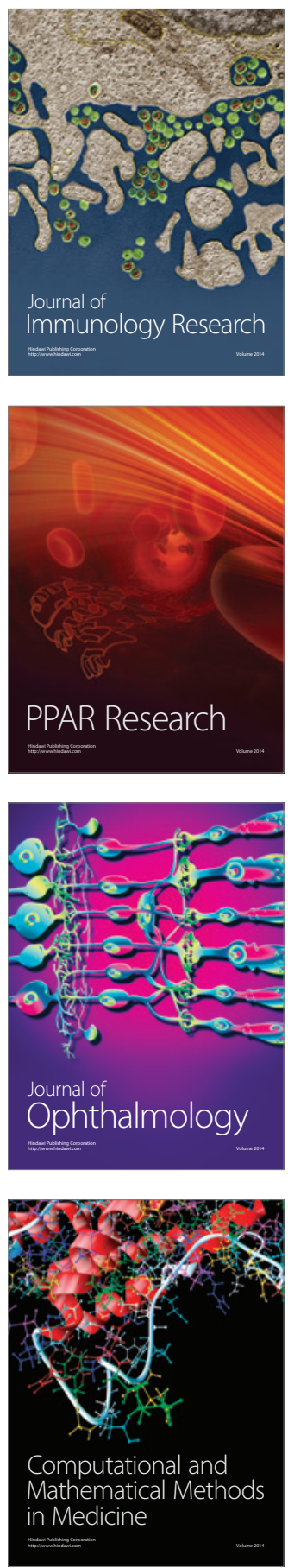

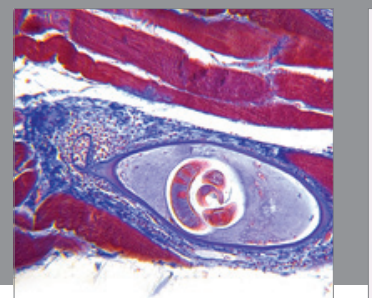

Gastroenterology

Research and Practice
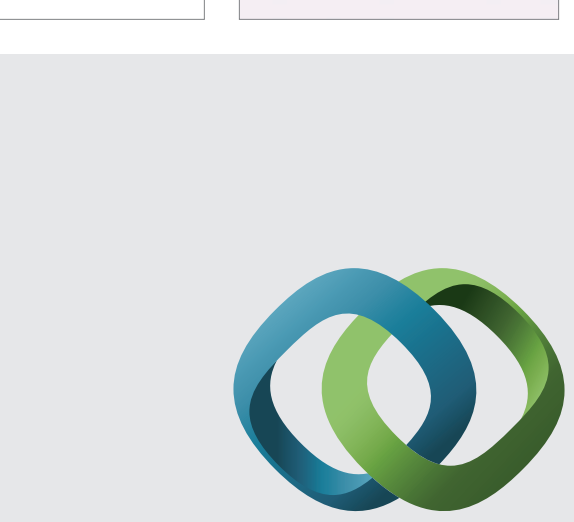

\section{Hindawi}

Submit your manuscripts at

http://www.hindawi.com
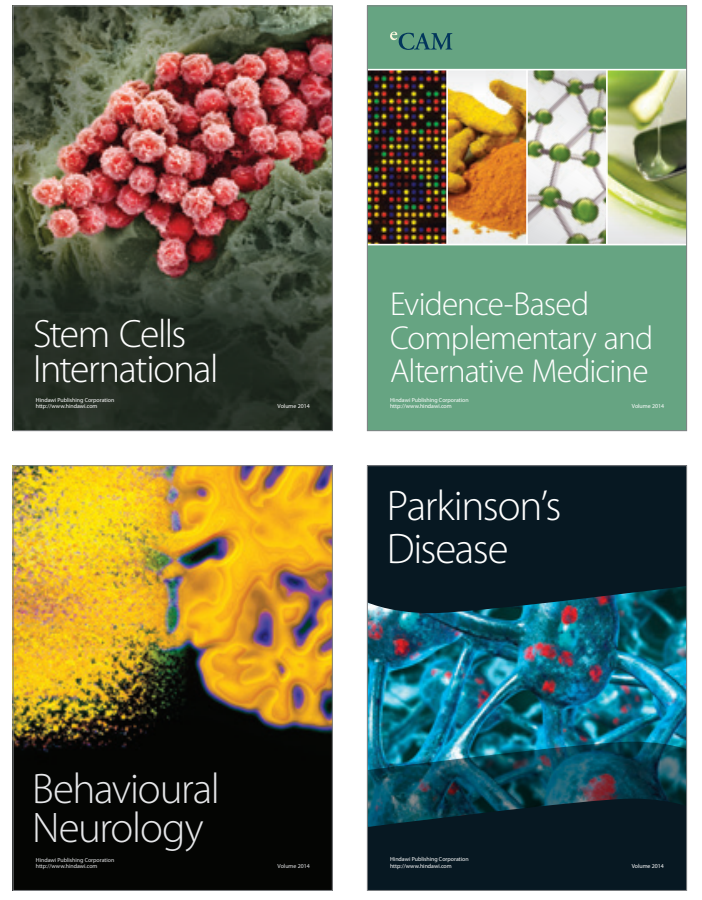
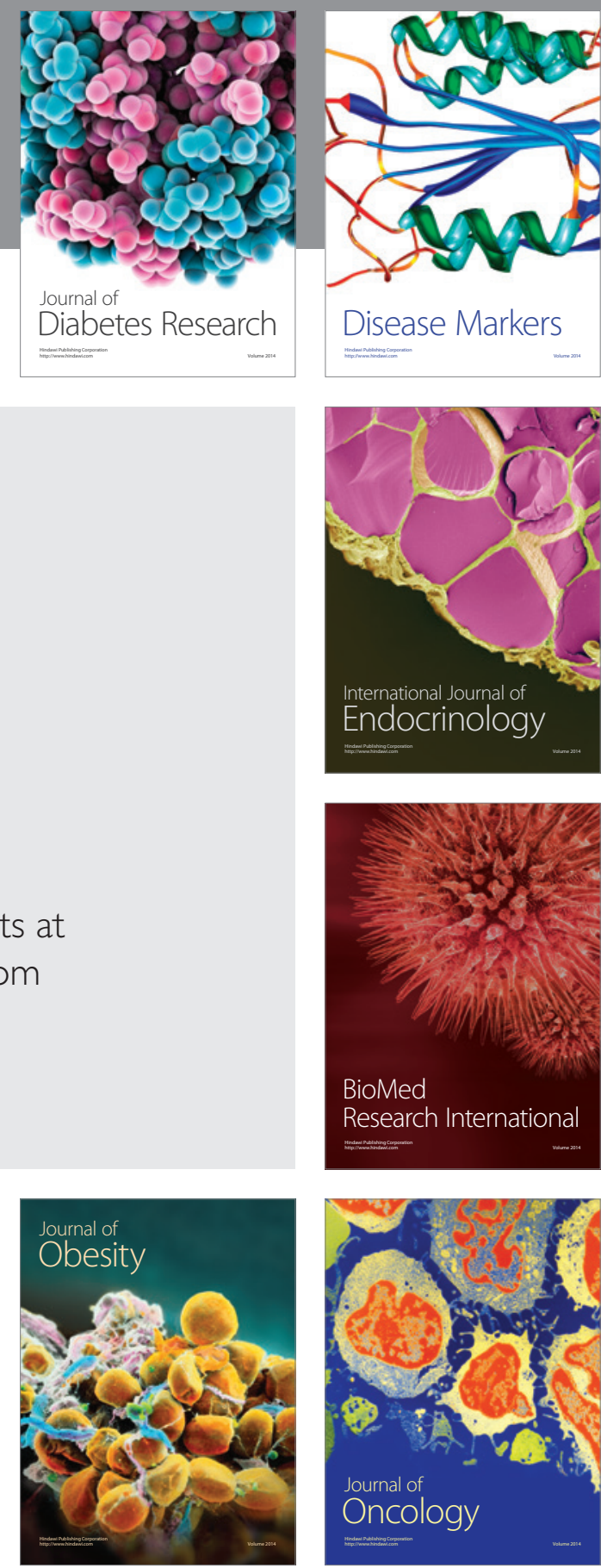

Disease Markers
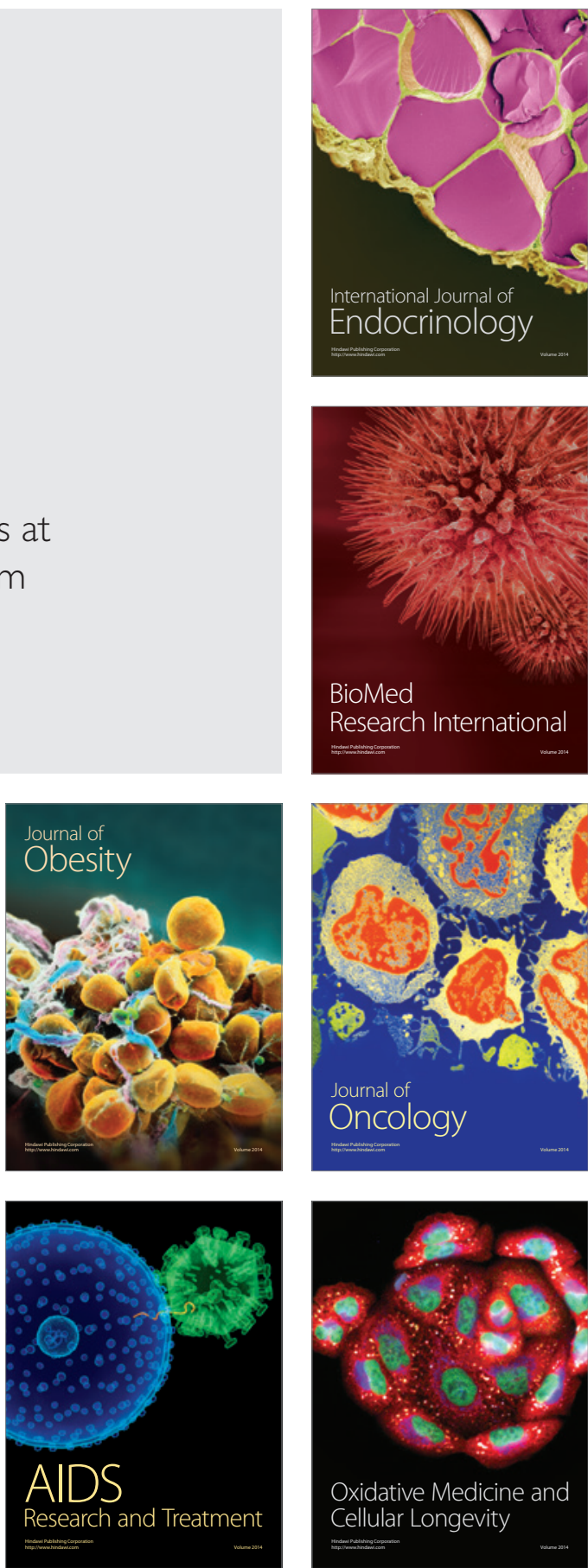